\title{
Gastrointestinal passage time of seeds ingested by captive Japanese martens Martes melampus
}

\section{$\operatorname{AUTHOR}(\mathrm{S}):$}

Tsuji, Yamato; Shiraishi, Toshiaki; Miura, Sayako

\section{CITATION:}

Tsuji, Yamato ... [et al]. Gastrointestinal passage time of seeds ingested by captive Japanese martens Martes melampus. Acta Theriologica 2011, 56(4): 353-357

\section{ISSUE DATE:}

2011-10

URL:

http://hdl.handle.net/2433/148239

\section{RIGHT:}

The final publication is available at www.springerlink.com; この論文は 著者最終稿です。内容が印刷版と異なることがありますので、引用の 際には出版社版をご確認ご利用ください。This is the Accepted Author Manuscript. Please cite only the published version. 
Tsuji et al. 1

1 Gastrointestinal passage time of seeds ingested by captive Japanese martens Martes

2 melampus

3 Yamato TSUJI, Toshiaki SHIRAISHI, and Sayako MIURA

4 The time it takes for ingested seeds to pass through the gut of animals is an important

5 aspect of endozoochorous seed dispersal because it influences seed dispersal distance.

6 Variations in the physical characteristics of seeds, such as their weight, volume, and

7 specific gravity, can affect their movement through the gastrointestinal system of a given

8 animal. We conducted feeding experiments with captive Japanese martens, Martes

9 melampus $(n=4)$, at Toyama Municipal Family Park Zoo, central Japan, to examine the

10 effects of the physical characteristics of seeds on their passage times. The mean $( \pm \mathrm{SD})$

11 transit time, mean retention time, and time of last appearance of four different types of

commercial seeds were $2.6 \pm 0.3 \mathrm{hr}$ (range: $0.6-5.4), 9.7 \pm 1.1 \mathrm{hr}(3.8-17.3)$, and 23.8

$13 \pm 3.1 \mathrm{hr}(12.2-51.8)$, respectively. All of these values are greater than those found during

14 previous experiments conducted with mustelids. Similar to previous studies, however, 
16 seeds. Our results thus indicate that martens disperse seeds of different plant species,

17 whose size, volume, and specific gravity all fall within the range of those used in the

18 present study, from parent plants at similar distances.

19

20 Primate Research Institute, Kyoto University, Aichi 484-8506, Japan, e-mail:

21 ytsuji@pri.kyoto-u.ac.jp (YT); Toyama Municipal Family Park Zoo, Toyama 930-0151, Japan (TS, SM)

24 Key words: feeding experiments, Martes melampus, physical characteristics, seed

25 dispersal

26 Running page headline: Seed passage time of Japanese martens 
Tsuji et al. 3

27

28

29

30

31

Introduction

The physical characteristics of seeds, such as size, weight and specific gravity, vary

among plant species. These variations can have a significant impact on passage time

through the gut of a given animal (Traveset 1998). Leavy and Grajal (1991), for example,

showed a negative correlation between the size of seeds ingested by cedar waxwings

Bombycilla cedrorum and their subsequent passage times. Smaller seeds would thus be

dispersed farther from parent plants. In contrast, Julliot (1996) provided evidence of a

positive correlation between seed size and passage time in red howler monkeys Alouatta

seniculus. To further confuse the issue, the relationship between passage time and

specific gravity, another physical characteristic relevant to seed dispersal, was positive

for seeds ingested by Japanese macaques Macaca fuscata (Tsuji et al. 2010) but negative

for those ingested by two species of tamarin monkeys Saguinus mystax and S. fuscicollis

(Garber 1986). Other studies have found no clear relationships between the physical

characteristics of seeds and their passage times (emus Dromaius novahollandiae: Wilson

1989; arctic foxes Alopex lagopus: Graae et al. 2004; Pampa foxes Lycalopex 
Tsuji et al. 4

42

43

gymnocercus and crab-eating foxes Cerdocyon thous: Varela and Bucher 2006). Thus, it

appears that the effects of physical characteristics on seed passage time vary among

animal species, and this may reflect variation in the size and/or morphology of the

digestive system and the digestive strategies of the animals under investigation.

Mustelids are generally regarded as carnivorous, but they also commonly consume

large amounts of fruit (Rosalino and Santos-Reis 2009), often voiding intact seeds with

their feces (pine martens Martes martes: Schaumann and Heinken 2002; stone martens $M$.

foina: Schaumann and Heinken 2002; Japanese martens M. melampus: Arai et al. 2002;

Koike et al. 2008; yellow-throated martens M. flavigula: Zhou et al. 2008a). The passage

of seeds through the guts of martens can have a positive effect on germination and/or

seedling growth (Hickey et al. 1999, Schaumann and Heinken 2002, but see Rosalino et

al. 2010). Therefore, the marten appears to be an important seed disperser within its

habitat (Hickey et al. 1999). Since mustelids travel between several hundred meters and several kilometers daily (Hickey et al. 1999, Zalewski et al. 2004), and have relatively

large home ranges amounting to between 1 and $4 \mathrm{~km}^{2}$ (Zalewski and Jedrzejewski 2006), 
Tsuji et al. 5

57 variation in passage time can markedly affect seed dispersal distance, which in turn

58 affects the seed shadow of a given plant species. Thus, evaluating the effects of the

59 physical characteristics of seeds on passage time through marten digestive tracts is

60 essential to understanding their role in endozoochorous seed dispersal.

61 In this study we conducted feeding experiments with captive Japanese martens,

62 which are considered an important mammalian seed disperser throughout Japanese

63 forests (Kusui and Kusui 1998, Otani 2002, Koike et al. 2008, Tsuji et al. in press). We

64 tested one simple prediction: that seed passage time through the gut of Japanese martens

65 differs among seed types because of variation in their weights, volumes, and specific

66 gravities.

67

68 Materials and methods

69 Four adult martens (three males and one female) with which we conducted our

70 feeding experiments were housed at the Toyama Municipal Family Park Zoo, central

71 Japan. All animals were reared in individual wire mesh pens (length $1.80 \mathrm{~m} \times$ width $1.8 \mathrm{~m}$ 
Tsuji et al. 6

$72 \times$ height $2.8 \mathrm{~m}$ ), and were active and in good condition. The estimated ages and body

73 weights of the three animals for which data were available (two males and one female,

respectively) were 16,3 , and $3 \mathrm{yr}$ and $2.0,1.8$, and $1.0 \mathrm{~kg}$. The female marten was neither

lactating nor pregnant during the study period. The martens were normally fed dead

chicks, chicken heads, boiled sweet potatoes and fresh fruit (fresh weight: $230-300 \mathrm{~g}$.

individual $^{-1}$ ) once a day (at 10:00). We only entered the pen during the experiments, to

minimize stressing the animals and thereby affecting gut passage times. About one month

before conducting the experiments, we set security cameras on the roofs of each pen to

continuously monitor the movements of each animal. Videos were continuously recorded

onto hard disks, so we could accurately record their defecation times and locations (see

below). 
Tsuji et al. 7

87 plant species on which martens are known to ingest in the wild. Because of restrictions

relating to experimentation with captive animals, we could not provide seeds collected in

89 wild in this study. We measured the length, width, and height of 30 randomly-picked

90 seeds with a vernier caliper (THS-30, Niigata Seiki Co., Japan) to the nearest $0.05 \mathrm{~mm}$.

91 We also weighed 30 randomly-picked dry seeds with an electric balance (UX4200H,

92 Shimadzu Co., Japan) to the nearest $1 \mathrm{mg}$. We then calculated seed volume according to

93 the formula:

94

$$
V=\pi R^{2}\left(L-\frac{2}{3} R\right)
$$

where $R=$ (seed width + height $) / 4$, and $L=$ seed length (Garber 1986). Finally, we

96 calculated the specific gravity of seeds $\left(\mathrm{mg} \cdot \mathrm{mm}^{-3}\right)$ by dividing the seed volume by the

97 seed weight (Table 1). After taking these measurements, we put seeds into the stomachs

of dead chicks, since preliminary experiments showed that the martens would not ingest

99 the seeds alone. We must thus accept the possibility that this treatment might have

100 affected the results of our experiments. Information concerning the size, weight, and

101 amount of seeds used in each experiment is shown in Table 1. 
Tsuji et al. 8

102

103

104

105

106

107

108

109

110

111

sample from the videos taken for each animal.

We conducted four experimental sessions between late September and early October,

2010. We did not change the martens' housing conditions or diet composition during the

experiments. Our methodology adhered to Japan's legal requirements for animal welfare.

On the first day of a given experiment, each animal was fed as usual at 10:00, and we

regularly entered the pen twice a day (10:00 and 16:00) to collect both non-ingested seeds

and all feces found within the enclosure. We recorded the locations of defecation and

cleaned the floor of the pen in order to facilitate subsequent monitoring of defecation

events. We rinsed fecal samples with water immediately after collection and screened

them using a $0.5 \mathrm{~mm}$ sieve, recording the number of intact seeds, defined as those with

undamaged embryos, whenever present. We considered seeds that were ingested but not

observed in faecal samples to be destroyed through mastication or digestion. We initiated

subsequent experimental sessions after $24 \mathrm{hr}$ had passed since the onset of the previous

experimental session (i.e., 10:00). We recorded the time of defecation for each fecal

According to previous studies of seed dispersal, the quantitative evaluation of seed 
Tsuji et al. 9

117 passage time is based on three parameters: transit time, mean retention time, and time of

118 last appearance. We obtained the mean retention time via the following formula:

$$
M R T=\sum_{i=1} m_{i} t_{i} / \sum_{i=1} m
$$

120 where $M R T=$ mean retention time, $m_{i}=$ the number of seeds excreted in the $i$ th defecation

121 at time $t_{i}(\mathrm{hr})$ after ingestion (Lambert 2002).

122 We tested the effects of seed type on the percentage of seeds recovered and on the

123 three passage time variables (transit time, mean retention time, and time of last

appearance), and the effects of individual marten on the passage times. We employed

125 Friedman's two-way ANOVAs to account for the non-normality of our data. We used

126 Spearman's correlation analyses to test for relationships between the physical

127 characteristics of seeds and both the percentage of seeds recovered and the three passage

128 time variables. We could not test for differences in seed recovery and passage time

129 variables between sexes because of our small sample size of four animals. We set the

130 level of significance for these analyses $(\alpha)$ at 0.05 . All data analyses were conducted

131 using the statistical software R version 2.9.1 (R Development Core Team 2009). 
133 Results

The martens in our study readily and immediately consumed the dead chicks when

135 presented with them, but not all of the seeds concealed therein were ingested because

136 several dropped out of the chick during feeding (Table 1). The martens defecated more

137 than half of their ingested seeds, The mean percentage of seeds recovered for each seed

138 type ranged from $70-86 \%$, and did not vary significantly among seed types (Friedman's

139 two-way ANOVA, $\left.\chi^{2}=4.3, p=0.233, \mathrm{df}=3\right)$ or among animals $\left(\chi^{2}=4.9, p=0.181, \mathrm{df}=\right.$

1403 ). Furthermore, none of the physical dimensions of the seeds correlated with the

141 percentage of seeds recovered (Spearman's correlation analyses, dry weight: $r_{s}=-0.20, p$

$142=0.917$; volume: $r_{s}=0.40, p=0.750$; specific gravity: $r_{s}=-0.40, p=0.750, \mathrm{df}=2$ for all

143 analyses).

$1450.3 \mathrm{hr}$ (range: $0.6-5.4 \mathrm{hr}$, Fig. 1a), $9.7 \pm 1.1 \mathrm{hr}(3.8-17.3 \mathrm{hr}$, Fig. 1b) and $23.8 \pm 3.1 \mathrm{hr}$

$146(12.2-51.8 \mathrm{hr}$, Fig. 1c), respectively. We treated the three passage time variables as 
147 independent of each other because there were no significant correlations among them

148 (Spearman's correlation analyses, transit time vs mean retention time: $r_{s}=-0.20, p=$

149 0.917; transit time vs time of last appearance: $r_{s}=-0.20, p=0.917$; mean retention time vs

150 time of last appearance: $r_{s}=-0.20, p=0.917, \mathrm{df}=2$ for all analyses). None of these

151 passage time variables differed significantly among seed types (Friedman's two-way

152 ANOVA, transit time: $\chi^{2}=1.5, p=0.682$; mean retention time: $\chi^{2}=1.2, p=0.753$; time of

153 last appearance: $\chi^{2}=2.1, p=0.552, \mathrm{df}=3$ for all analyses). Among these variables, mean

ANOVA, $\chi^{2}=9.9, p=0.019, \mathrm{df}=3$ ), being longest in the heavier males and shortest in the

lighter female. Finally, transit time and time of last appearance did not differ between

individual animals (transit time: $\chi^{2}=4.4, p=0.219$; time of last appearance: $\chi^{2}=5.7, p=$

Discussion 
162

163

164

165

166

seed types in our experiments. Our results differ from those concerning other animal

species such as birds (Leavy and Grajal 1991) and primates (Garber 1986, Tsuji et al.

2010), in which the physical characteristics of seeds were shown to affect passage times.

Our results imply that plant seeds with physical characteristics falling within the ranges

of those used in the present study have the same probability of being dispersed by

Japanese martens a similar distance away from parent plants. Previous studies of

carnivorous mammals have also showed that the passage times of seeds ingested by their

subject animals did not vary across seed types (Graae et al. 2004, Varela and Bucher 2006,

Zhou et al. 2008b). Thus, the lack of a relationship between seed type and passage time

appears to be a common trait of carnivorous mammals. However, we cannot deny the

possibility that our results might have been affected by our small number of experiments.

Another possibility is that factors that we did not consider in this study, such as fruit pulp

properties (e.g. texture and chemistry), the amount of other fiber-rich compounds of the

wild marten diet (e.g., meat and fur), and the amount and/or shape of seeds, may have

masked the effects of seed size, volume, and specific gravity. Thus, further and more 
178 (Traveset 1998). We also encourage cooperation between researchers and zoological

gardens, as this will be invaluable in furthering our understanding of endozoochorous

seed dispersal among carnivorous mammals. studies to date evaluating ranging patterns among Japanese martens (Kawauchi et al. 2003, Okumura and Kitahara 2006). Furthermore, few studies have tested the effects of ingestion and passage through the digestive systems of Japanese martens on the study can contribute to an estimation of the seed shadows created by Japanese martens. To be an effective seed disperser, fruit consumers cannot destroy the seeds they ingest, but they are also expected to enhance (or at least have a neutral effect on) seed 

evaluation of the efficacy of Japanese martens as seed dispersers. grateful to M.A. Huffman and A.J.J. McIntosh, and three anonymous reviewers for proofreading and generally improving this manuscript.

Arai S., Adachi T., Kuwahara Y. and Yoshida K. 2003. Food habit of the Japanese marten 

155-170.

Graae B. J., Pagh S. and Bruun H. H. 2004. An experimental evaluation of the arctic fox (Alopex lagopus) as a seed disperser. Arctic, Antarctic, and Alpine Research 36: 468-473. Oikos 87: 499-508. tropical rain forest of French Guiana. International Journal of Primatology 17: 239-258. testosterone concentration, home range and active time in wild male marten, Martes melampus melampus. Honyurui Kagaku 43: 93-98. [In Japanese with English summary] 
Koike S., Morimoto H., Goto Y., Kozakai C. and Yamazaki K. 2008. Frugivory of carnivores and seed dispersal of fleshy fruits in cool-temperate deciduous forests.

Lambert J. E. 2002. Digestive retention times in forest guenons (Cercopithecus spp.) with reference to chimpanzees (Pan troglodytes). International Journal of Primatology 23: 1169-1185.

Leavy D. J. and Grajal A. 1991. Evolutionary implications of fruit-processing limitation in cedar wax wings. American Naturalist 138: 171-189.

236 Okumura T. and Kitahara M. 2006. Food habits and home range of sympatric red fox and 
Otani T. 2002. Seed dispersal by Japanese marten Martes melampus in the subalpine shrubland of northern Japan. Ecological Research 17: 29-38.

Pollux B.J.A., Ouborg N.J., van Groenendael J.M. and Klaassen M. 2007. Consequences of intraspecific seed-size variation in Sparganium emersum for dispersal by fish.

244 R Development Core Team. 2009. R: A language and environment for statistical computing. Version 2.9.1. R Foundation for Statistical Computing, Vienna, Austria.

246 Rosalino L.M. and Santos-Reis M. 2009. Fruit consumption by carnivores in Mediterranean Europe. Mammal Review 39: 67-78. 
Tsuji Y., Morimoto M. and Matsubayashi K. 2010. Effects of the physical characteristics of seeds on gastrointestinal passage time in captive Japanese macaques. Journal of Zoology 280: 171-176. mustelids, Martes melampus and Mustela itatsi, in western Tokyo, central Japan. Mammalian Biology. ingested by foxes. Journal of Arid Environment 67: 566-578. 

other European woodlands. Ecography 29: 31-43. seed dispersal by the yellow-throated marten, Martes flavigula, in a subtropical forest of China. Journal of Tropical Ecology 24: 219-223.

273 Zhou Y. B., Zhang L., Kaneko Y., Newman C. and Wang X. 2008b. Frugivory and seed dispersal by a small carnivore, the Chinese ferret-badger, Melogale moschata, in a 
Tsuji et al. 20

$277 \quad$ Figure legends

278 Figure 1: Relationships between seed type $(n=4)$ and passage time variables: a) transit

279 time, b) mean retention time, and c) time of last appearance of a seed. Filled circles

280 indicate mean values and bars indicate standard deviations. 

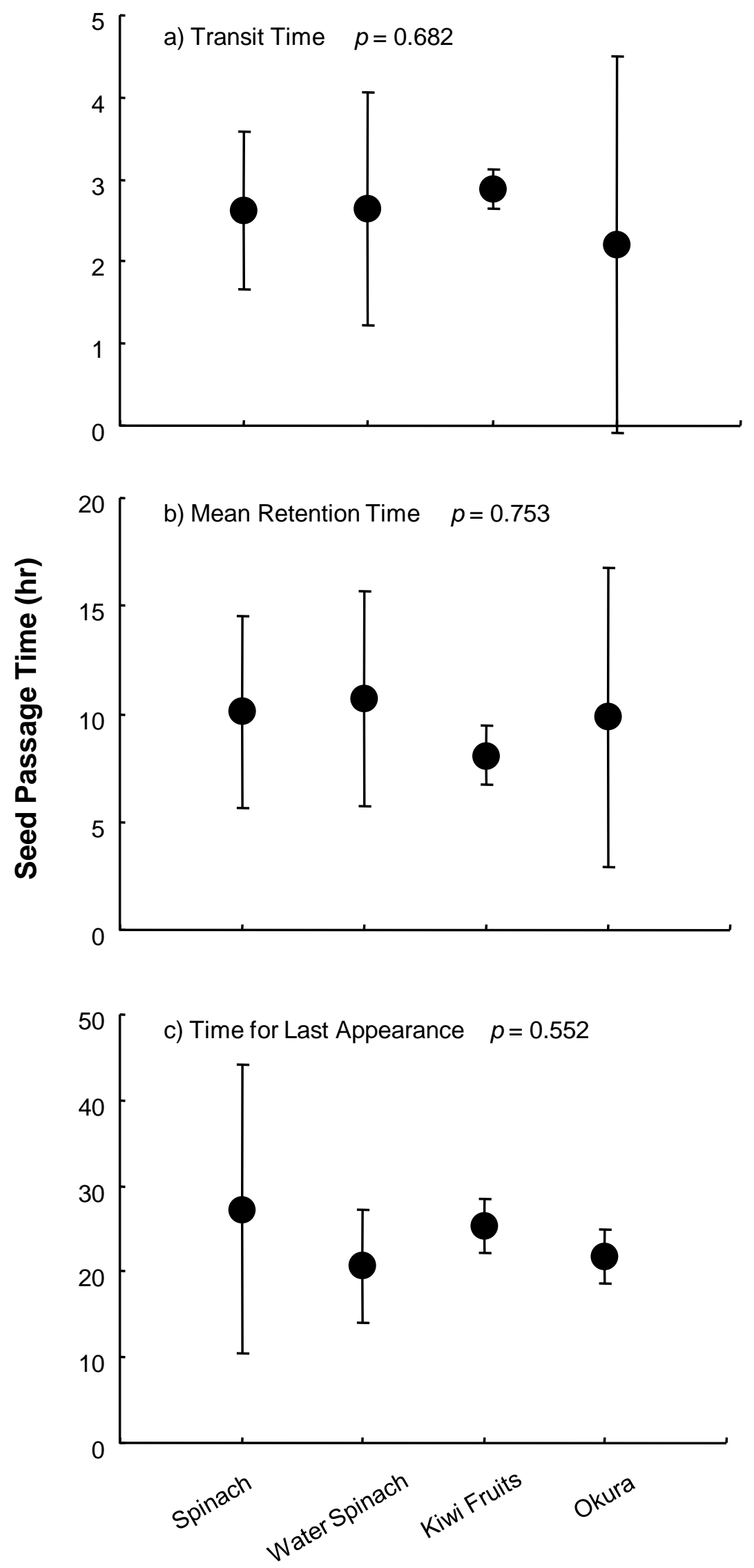
Table 1. The physical characteristics of commersial seeds used in feeding experiments and their fate.

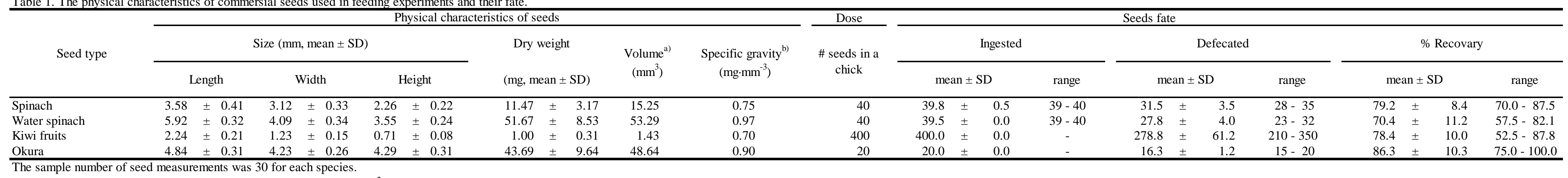

The seed volume was calculated by using the following formula: $V=\pi R^{2}(L-2 / 3 R) ; \mathrm{V}=$ volume, $\mathrm{R}=$ (width + height) $/ 4, \mathrm{~L}=$ length

b) Calculated as dry weight / volume. 